\title{
La reparación cultural: un avance ineludible en la justicia transicional
}

\section{Cultural repair: an ineludible advance in transitional justice}

Fernando Charria-García ${ }^{1}$

\begin{abstract}
Resumen
Se presenta una iniciativa dentro de la justicia transicional que denominamos "reparación cultural". La "reparación simbólica" contempla aquellos casos donde existe una intención de asignar valores económicos para reparar a las víctimas. Frente a la imposibilidad de hacerlo, la Corte Interamericana de Derechos Humanos amplió este concepto a través de un deslizamiento de sentido que, consideramos, puede denominarse como "reparación cultural".

Este tipo de reparación podría ser implementada en comunidades con fuertes características de identidad, como las indígenas, las afrodescendientes y otras más pequeñas con rasgos identitarios marcados. Esto implicará dialogar con las víctimas y construir con ellas para impactar en las instituciones sociales según la cultura de dicha comunidad, de modo tal que surjan formas de reparación que morigeren el dolor individual y colectivo, es decir, poder dar respuestas que construyan puentes para que puedan abandonar la condición de víctima y construirse como sujetos.
\end{abstract}

Palabras clave: justicia transicional, reparación simbólica, víctimas, cultura, reparación cultural.

\begin{abstract}
An initiative is presented within the transitional justice that we call "cultural reparation". "Symbolic Reparation" contemplates those cases in which there is an intention to assign economic values to repair the victims. Faced with the impossibility of doing so, the Inter-American Court of Human Rights has generated what is known as "symbolic reparation", a concept that is tending to expand, situation that we consider through a shift of meaning, that can be called "Cultural Reparation".

This type of reparation could be implemented in communities with strong identity references such as indigenous communities, communities of African descent, or smaller communities with very marked identity traits. This will involve dialogue with the victims and growing with them, in order to impact social institutions according to the culture of that community, so that forms of reparation can emerge that ease individual and collective pain, that is, the ability to provide responses that build bridges so that they can abandon their condition as victims and build themselves as subjects.
\end{abstract}

Keywords: transitional justice - symbolic repair victims - culture - cultural reparation

\section{Derecho / Ensayo científico}

Citar: Charria-García, F. (2020). La reparación cultural: un avance ineludible en la justicia transicional. Omnia. Derecho y sociedad, 3 (3), pp. 37-54.

\footnotetext{
${ }^{1}$ Universidad Externado de Colombia. Perfil académico y profesional: abogado (Universidad Externado de Colombia); magíster en Estudios Políticos de la Pontificia Universidad Javeriana de Cali; doctor en Derecho y Ciencias Sociales, con cursos del Doctorado en Derecho de la Cultura, ambos de la UNED de España; autor de seis libros en el campo del derecho de la cultura; docente investigador de la Facultad de Derecho de la Universidad Libre, sede Cali, Colombia. fernandocharriagarcia@gmail.com. ORCID: http://orcid.org/0000-0002-0195-907.
} 


\section{PRESENTACIÓN}

El interés por la idea de "reparación cultural" surgió durante el trabajo para escribir la tesis de grado a los fines de obtener el título de abogado. En esa oportunidad, tuvimos ocasión de trabajar con una comunidad indígena de Colombia entre los años 1978 y 1983. Esta experiencia nos dejó la inquietud de conocer más sobre los aspectos jurídicos de los sistemas indígenas en Colombia, lo cual suponía una metodología de investigación más etnográfica que documental. Así, podemos decir que ese trabajo monográfico fue un elemento importante para inquietar en el alma mater las formas investigativas y acercarnos a lo que hoy en día conocemos como "investigación sociojurídica".

Así las cosas, nuestras motivaciones para estas reflexiones han sido contribuir, de algún modo, al reconocimiento vinculado con las comunidades indígenas y afrodescendientes en Colombia (incrementó esta curiosidad lo que está pasando actualmente en el país respecto de la justicia transicional) y efectuar una propuesta que ayude en la construcción de la democracia, en particular, en aquellas comunidades con fuertes rasgos identitarios que han sufrido permanentes violaciones de sus derechos humanos y colectivos.

\section{INTRODUCCIÓN}

No hablaremos en profundidad sobre justicia transicional pues no es el objetivo de este trabajo. Simplemente, delinearemos algunos de sus elementos. Entendemos que es una forma de justicia que se aplica en aquellos lugares donde ha habido una sistemática violación de derechos humanos para proponer un tránsito hacia la democracia. En otras palabras,
La justicia transicional es una respuesta a las violaciones sistemáticas o generalizadas a los derechos humanos. Su objetivo es reconocer a las víctimas y promover iniciativas de paz, reconciliación y democracia. La justicia transicional no es una forma especial de justicia, sino una justicia adaptada a sociedades que se transforman a sí mismas después de un período de violación generalizada de los derechos humanos. (Patiño, 2010, p. 53)

Realizaremos un acercamiento a esta concepción con el ánimo de dar un espacio referencial a la noción de reparación simbólica, punto de partida de nuestra reflexión.

Se habla de reparación simbólica solamente al interior de los procesos de justicia transicional que propone cuatro pilares como referentes: verdad, justicia, reparación y garantías de no repetición. Estos pilares deben ser asumidos en su integridad si lo que se quiere realmente es construir un verdadero camino que conduzca una sociedad que ha venido manifestando permanentes violaciones a los derechos humanos a convertirse en una democracia y que no se quede simplemente en una democracia delegativa (O'Donell, 1995).

Como camino hacia la democracia, la justicia transicional implica judicializar a los victimarios, atender las necesidades de las víctimas y construir una verdad sociohistórica. En el informe del secretario general de la ONU al Consejo de Seguridad, se la define como "el conjunto de procesos y mecanismos asociados con el intento de una sociedad de enfrentarse y superar un pasado de abusos a gran escala para asegurar la responsabilidad, obtener justicia y lograr la reconciliación" (Escudero, 2015, p. 101). Por ello, los mecanismos de justicia transicional deben ceñirse a los principios y las normas internacionales que orientan la lucha 
contra la impunidad que cobran sentido si son utilizados de manera integral.

En cuanto a la reparación, podemos decir que desde el Código de Hammurabi (1670 años antes de nuestra era, aproximadamente) se incluyó la idea de la compensación en dinero por los daños sufridos contra la persona, mientras que la Lex XII tabularum contempló la composición voluntaria, mediante la cual el sujeto podía optar por devolver el mal sufrido o exigir un resarcimiento monetario, y la composición obligatoria, compuesta de una pena y una reparación. En la pena, quien ocasionaba el daño pagaba una suma de dinero en lugar de sufrir las acciones sobre su propio cuerpo. En Roma, al emplear el método casuístico e incorporar acciones mixtas que perseguían una pena y una indemnización, comenzaron a unificarse estas dos ideas que, sin embargo, no establecieron un principio general de responsabilidad.

En las leyes bárbaras (de las cuales la más conocida es la Ley Sálica), se consagraron tarifas de composición, según la naturaleza del daño y la persona, fijando una sanción denominada wergeld.

En el código civil francés de 1804, se estableció el principio de la responsabilidad civil que vincula la reparación del daño con el costo del perjuicio sufrido (Nanclares y Gómez, 2017).

En otras palabras, en general e históricamente, se puede afirmar que existe una relación entre el daño causado en contra de lo jurídicamente establecido y la reparación, cuyo hilo de causalidad es precisamente una obligación por parte del causante del daño en favor del afectado, con la pretensión de que el causante responda a efectos de poner al lesionado en la posición que tenía antes de ser afectado.

En el caso de la justicia transicional, lo primero que se debe señalar es que se estructura sobre el reconocimiento de que se trata de un derecho de las víctimas que se concreta en la posibilidad de interponer recursos y obtener reparaciones. Así,

las víctimas son titulares de un derecho a la
reparación integral por el daño sufrido (in-
demnización, restitución y rehabilitación),
sino también mediante medidas de satisfac-
ción o reparación moral (declaraciones de
asunción de responsabilidades, peticiones
institucionales de perdón, reconocimiento
al más alto nivel institucional del daño cau-
sado, etc.). (Escudero, 2015, p. 102)

Por definición, todas las reparaciones tienen un importante papel simbólico en el proceso de construir confianza pública y de reintegrar las víctimas a la sociedad.

No se puede pasar por alto la importancia de las garantías de no repetición. Estas se encuentran estrechamente imbricadas con la reparación integral, ya que esta exige un mayor ámbito de plenitud en su cumplimiento cuando las violaciones sistemáticas de derechos humanos se ejercen sobre aquellas personas y poblaciones que, por condiciones de debilidad frente a los agresores, no tienen posibilidades de ejercer la defensa de sus derechos o, al menos, esa defensa es insuficiente para detener al agresor.

\section{REPARACIÓN SIMBÓLICA Y PSICOLOGÍA}

Para el derecho, la reparación simbólica es un conjunto de medidas que no tienen connotación económica o que, en caso contrario, vuelve extremadamente difícil realizar una estimación económica del daño, de allí que el énfasis esté puesto en lo simbólico. En este sentido, el profesor Hinestrosa (s.f.) señala que en la reparación compensatoria no se paga el daño, se ofrece algo que deberá ayudar a mermar lo que se tuvo, en tanto ya no puede recuperarse lo que definitivamente se perdió. Cuestiones 
tales como el dolor, la aflicción o la amargura no tienen precio por ser sentimientos.

Por su parte, para la psicología, el elemento de lo simbólico obliga a realizar un acercamiento a la realidad factual del ser humano, pues es el ámbito donde este se constituye. En este sentido, ya desde Freud, se establecía la diferencia entre lo que se llama la realidad y lo que puede ser la realidad psíquica. Esta última se vincula con la hipótesis freudiana de los procesos inconscientes, ya que estos mecanismos no solo no tienen en cuenta la realidad exterior, sino que la sustituyen por una realidad psíquica. Por lo anterior, podríamos decir que, en su acepción más estricta, la expresión "realidad psíquica" designaría el deseo inconsciente y la fantasía que está ligada a este mismo deseo.

Posteriormente, fue Jacques Lacan (1953) quien realizó una especie de reescritura de este problema presentado por Sigmund Freud, en tanto planteó que el hombre, para poder ser humano, se organiza en tres dimensiones: lo imaginario, lo simbólico y lo real. Lacan comienza por definir lo que él entiende por la dimensión imaginaria, para lo cual recupera el concepto de imago de la teoría freudiana, en la cual lo imaginario sería deudor de lo especular que, en parte, es organizador del yo: “La imago permite al sujeto identificarse, quedar cautivado y fascinado por la imagen del otro en el estadio del espejo" (Lacan, 1971). Para comprender mejor esta idea, recuperemos la siguiente imagen: lo primero que ve un ante el espejo es la imagen de un niño, es decir, la imagen de otro. No obstante, acto seguido ( $y$, por lo general, ayudado por la madre) el niño se percata de que esa imagen que es observada al revés por él se trata de él mismo, pues así se lo confirma su madre $y$, finalmente, se da cuenta con el tiempo y con el proceso de sujeción social que ese que está en el espejo en realidad no es él, se trata del reflejo de la imagen de él. El verda- dero sujeto no es el del espejo, sino el que está afuera, el de carne y hueso, el del cuerpo que siente y percibe, el del cuerpo material que, por supuesto, también se nutre de la imagen.

Por otra parte, la dimensión simbólica remite a las experiencias del otro y del semejante. Cuando hablamos de personas, el otro sería el mundo del lenguaje porque alberga el verdadero tesoro de los significantes que, además, nos organiza con respecto a la cultura y a la ley que nos regula. Entonces, el sujeto (que es un individuo social producido a la medida de la sociedad que lo acoge la cual, a su vez, es también creada por este individuo social) obliga a una forma de organización que se impone a la psique: basta que "una cierta realidad se establezca como lo otro respecto del sujeto, para que el principio del placer sufra la distorsióntransformación de la que surgirá el principio de la realidad" (Castoriadis, 1993, p. 228).

El proceso de la institución social del individuo - es decir, de la socialización de la psique- es la imposición de la relación a los otros (que es siempre y a la vez tanto una fuente de placer satisfactoria como una fuente de displacer perturbadora) que implica una sucesión de rupturas infligidas. En estos casos, la psique genera un exterior para colocar en él el centro del displacer. Luego, esto se convertirá en un mundo y un objeto que es literalmente "proyección", que en su origen fue expulsión del displacer (Castoriadis, 1993).

En vinculación con lo anterior, cabe decir que el término "significante" proviene de la lingüística. Así, en Saussure (1993), el signo lingüístico es una entidad psíquica de dos caras: el significado o concepto (por ejemplo, para la palabra "árbol", la idea de "árbol" y no el referente, el árbol real) y el significante, que es también una realidad psíquica puesto que se trata no del sonido físico al pronunciar la palabra "árbol", sino de la imagen acústica de ese 
sonido que, por ejemplo, se puede tener en la cabeza cuando uno recita una poesía para sí, sin decirla en voz alta.

A estas nociones, Lacan añade la categoría o la dimensión de lo real. Esta dimensión remite a lo que está más allá del sujeto, a lo real de la ciencia o a lo real del cuerpo. De alguna manera, se podría decir que la realidad para el sujeto es el encuentro entre lo imaginario, lo simbólico y lo real. Por esto, el profesor Castoriadis (1993) dirá que la primera forma de la sociedad es su condición original de la cual surgirá la humanidad, que es una condición diferente a la original y que está construida sobre una madeja de significaciones. Este estrato original ya está ordenado, pero lo que por ahora nos importa es que lo que está ordenado y organizado no puede ser separado de aquel que lo organiza.

\section{LA REPARACIÓN EN DERECHOS FUNDAMENTALES}

En el derecho de la mayoría de los Estados occidentales, se comparte un paradigma que entiende que una vez realizada una afectación de este tipo de derechos a una o varias víctimas, se debe hacer uso de una serie de medidas que implican la restitución, la compensación y las garantías de no repetición. Con estas medidas, se pretende restaurar a las víctimas a las condiciones que tenían antes de ser afectadas en sus derechos $y$, frente a la imposibilidad de hacerlo, se emplea un sustituto que suele ser el dinero, para compensar y restituir.

La idea anteriormente expresada implica entender que los sujetos son iguales y que, por ello, tanto victimarios como víctimas se encuentran en igualdad de condiciones. Sin embargo, tal idea no es necesariamente real y la vida actual —signada por el desarrollo del capitalismo, el coronavirus pandémico y la globalización nos muestra que se ahondan progresivamente las inequidades. Así, se explica que, de acuerdo con el nuevo informe de Oxfam (2018),

El $82 \%$ del crecimiento de la riqueza mundial del último año ha ido a parar a manos del $1 \%$ más rico, mientras que a la mitad más pobre de la población mundial no le ha llegado nada de ese crecimiento. (p. 11)

En todo caso, tanto la restitución como la compensación son moralmente aceptables para el derecho, en la medida en que muestren su eficacia en la restauración de los máximos niveles de capacidades de las personas antes de ser afectadas por estas vejaciones. Señala Puccetti (2017): "la compensación no pretende otra cosa que otorgar a las víctimas algo que pueda ser equivalente al valor de lo que ha perdido, en tanto que la restitución tiene por objeto aquello que le ha sido quitado" (p. 47)

Es en la Convención americana sobre derechos humanos (Pacto de San José), (Organización de los Estados Americanos [OEA], 1969) que, en su artículo 63.1, se encuentra la base conceptual de la reparación integral, cuando señala:
Cuando decida que hubo violación de un derecho o libertad protegidos en esta Con- vención, la Corte dispondrá que se garanti- ce al lesionado en el goce de su derecho o libertad conculcados. Dispondrá asimismo, si ello fuera procedente, que se reparen las consecuencias de la medida o situación que ha configurado la vulneración de esos dere- chos y el pago de una justa indemnización a la parte lesionada. (art. 63.1)

A lo anterior, debemos vincular la idea de medidas de satisfacción o de reparación simbólica que ya no opera solamente sobre lo material, sino que asume una nueva órbita de reparación que no se encontraba tradicional- 
mente incluida dentro de las reparaciones. Se habla, así, de nuevos tipos de acciones de reparación, a saber: "medidas de reconocimiento" (el responsable de la violación efectúa un reconocimiento público de su responsabilidad), "medidas de determinación de responsabilidad" (se detiene el hecho delictivo y se facilita un acuerdo de reparación con las víctimas), "medidas de disculpa" (supone que la disculpa a las víctimas y a sus familiares se realice públicamente por parte del Estado responsable), "medidas de publicidad" (se busca que la sentencia en su totalidad o en algunas de sus partes deba realizarse por parte del Estado y en condiciones idiomáticas, de lugar y de medios de divulgación específicos) y "medidas de conmemoración" (en las que la alta corte (CIDH) ordena a los victimarios realizar actos en memoria de las víctimas lesionadas) (Rojas como se cita en Puccetti, 2017).

Entonces, estas medidas procuran reparar lo inmaterial a nivel no solo individual, sino también colectivo. Si bien para algunos puede representar un avance, para otros dicho avance genera una pugna respecto de la seguridad jurídica, lo cual es entendible, pero a su vez debatible en tanto que el derecho no puede ser concebido como un campo inamovible; al contrario, es un campo cambiante y de gran dinamismo, afectado por las circunstancias de tiempo, modo y lugar, lo cual hace posible el surgimiento de nuevas emergencias $y$, por ende, del requerimiento de nuevos planteamientos jurídicos, por lo cual la seguridad jurídica debe reajustarse permanentemente.

\section{EL CONCEPTO DE LA REPARACIÓN SIMBÓLICA DESDE UNA EXPERIENCIA EN ARGENTINA}

Es menester indicar que la República de Argentina ha vivido también un proceso de justicia transicional, a partir de las afectaciones sucedidas producto del golpe militar del 24 de marzo de 1976, cuando se constituyó una Junta Militar conformada por Videla, Viola, Galtieri $y$, por último, Bignone, período en el cual los servicios secretos de Argentina detenían, secuestraban, torturaban y asesinaban a los que eran considerados "peligrosos". Dicha junta gobernó la Argentina hasta el 10 de diciembre de 1983, fecha en la cual las elecciones dieron un giro hacia la democracia con la llegada al poder de Raúl Alfonsín.

Ahora bien, desde la perspectiva que aquí nos interesa, dentro de la justicia transicional que vivieron, fue posible que el Equipo de Salud Mental de CELS y Graciela Guilis escribieran su experiencia en lo relacionado con la reparación (Guilis et al., s. f.). Allí, señalaron que lo primero que debe comprenderse es que el adjetivo "simbólica" que se añade a la palabra "reparación" y que se produce en el campo de lo jurídico puede ser entendido de dos maneras. Por una parte, no hace referencia a lo que se ha perdido, sino a lo que representa, es decir, muestra que el daño en sí mismo es irreparable. Entonces, la reparación es simbólica porque pretende una compensación que siempre es un desplazamiento desde el daño real hacia un acto de justicia, pretende representarlo cualitativa o cuantitativamente, pero nunca repara el daño real producido sobre la víctima. Por otra parte, se habla de "reparación simbólica" porque, como acto reparatorio por parte de la justicia, depende de la relación absolutamente singular que la víctima establezca entre lo que la reparación le ofrece y aquello que la víctima ha perdido.

Por esto, la reparación nunca puede ser igual a lo perdido, frente a lo cual lo único que se puede hacer es generar una opción para que lo simbólico permita reestructurar el orden de lo perdido con un nuevo sentido, pues lo que se representa no es la cosa del mundo 
en sí (lo perdido), sino la recomposición que el psiquismo pueda hacer de dicha pérdida, un verdadero proceso de reinscripción continua de lo que representa.

Esto implica diferenciar el acto reparatorio que es lo que la justicia y la comunidad pueden propiciar de la reparación en sí misma.

\section{EL CONCEPTO DE REPARACIÓN SIMBÓLICA DES- DE UNA EXPERIENCIA EN COLOMBIA}

La concepción de perjuicio moral en Colombia fue reconocida mediante acciones jurisprudenciales hacia 1920. En este sentido, se convierten en referentes obligados la decisión de la Corte Suprema de Justicia en el caso de Villaveces, quien demandó a Bogotá para que la condenaran a devolver los restos de su esposa (Emilia Santamaría), los cuales — sin autorización alguna- habían sido exhumados y depositados en una fosa común. Ante esta circunstancia, la Honorable Corte reconoce un daño moral que debe ser reparado según los artículos 2341 y 2356 del Código Civil (Mancipe González, 2005).

Posteriormente, la Corte Suprema de Justicia, el 23 de abril de 1947, en sentencias publicadas en la gaceta judicial tomo LI n¹971 y 1972, señaló que el daño moral podía ser objetivado, por lo que se estará ante un perjuicio moral objetivado, como cuando se afecta o se lesiona un interés de carácter extrapatrimonial o inmaterial que tiene repercusiones en el patrimonio de la víctima y genera un detrimento en él y, subjetivo, cuando la lesión se efectúe sobre aquellos aspectos sentimentales íntimos de una persona y que afectan intereses extrapatrimoniales o inmateriales. Es el daño moral puro, o daño al patrimonio afectivo de la víctima, si el daño se proyecta sobre la vida social o de relación del afectado (Mancipe González, 2005).

El perjuicio moral ha sido entendido por el Consejo de Estado como:
En relación con el perjuicio moral ha reiterado la Sala que la indemnización que se reconoce a quienes sufran un daño antijurídico tiene una función básicamente satisfactoria y no reparatoria del daño causado y que los medios de prueba que para el efecto se alleguen al proceso pueden demostrar su existencia pero no una medida patrimonial exacta frente al dolor, por lo tanto, corresponde al juez tasar discrecionalmente la cuantía de su reparación, teniendo en cuenta la gravedad del daño causado al demandante. (Consejera Ponente Dra. Ruth Stella Correa Palacio como se cita en Mancipe González, 2005, p. 73)

Como afirma este autor (Mancipe, 2005), el problema de la reparación que afecta intereses inmateriales busca hacer más llevadera la pena, pues nunca la situación de la víctima podrá ser igual ni se podrá reestablecer a la situación en que se encontraba antes de haber sufrido la lesión. Esto implica un importante desprendimiento por parte del daño moral respecto de su equivalencia económica para dar paso a otro tipo de reparación, que es lo que aquí nos interesa.

Además, el Consejo de Estado en su evolución ha reconocido en el caso de muerte de dos o más seres queridos un daño moral mucho más profundo que el normal, lo cual da pie a pensar en aquellos daños infligidos a una población y preguntarse, frente a ello, si es posible pensar que pueda ser objeto de reparación o mitigación.

El trabajo realizado por un grupo de profesionales en la población de Trujillo (Valle del Cauca, Colombia) nos permite identificar algunos referentes que consideramos importantes (Botero, Solis, López y Velásquez, 2000).

Se parte de afirmar que el sujeto humano individual es también un sujeto social. Entonces,

Omnia. Derecho y sociedad, núm. 3, 2020: 37-54 
el concepto de "sujeto" resulta esencial para establecer que, de esa obligatoria experiencia de relación con el otro, la existencia humana no es otra cosa que la asistencia a la imposibilidad de existir por fuera de la relación con ese otro. En relación con esto, afirma Lacan (1987):

La discontinuidad es, pues, la forma esencial en que se nos aparece en primer lugar el inconsciente como fenómeno, la discontinuidad en la que algo se nos aparece como vacilación. Ahora bien, si esta discontinuidad tiene ese carácter absoluto, inaugural en el camino que tomó el descubrimiento de Freud, ¿habremos de colocarla -como después tendieron a hacerlo los analistassobre el telón de fondo de una totalidad? ¿Es el uno anterior a la discontinuidad? No lo creo, y todo lo que he enseñado estos años tendía a cambiar el rumbo de esta exigencia de un uno cerrado, espejismo al que se aferra la referencia a un psiquismo de envoltura, suerte de doble del organismo donde residiría esa falsa unidad. Me concederán que el uno que la experiencia del inconsciente introduce es el uno de la ranura, del rasgo, de la ruptura. (p. 33)

Parte de lo interesante de esta afirmación es que se relaciona con la idea aristotélica del zôon politikón, puesto que se entiende que el hombre, para poder ser un verdadero ser humano, debe por razón de natura vivir con otros seres humanos en sociedad. Tal razón no significa que, por ello mismo, deba dejar de aprender a vivir con las otras personas en sociedad, implica que necesita vivir con otras personas, que debe aprender a vivir con esas otras personas particulares o específicas, y que debe relacionarse, al menos, en cuatro niveles diferentes:

1. Con los otros, es decir con las otras personas, los animales y las plantas. e-ISSN 2618-4699
2. Con lo Otro, en otras palabras, con las cosas, los fenómenos y las ideas.

3. Consigo mismo, es decir, con el mundo interior con el pretexto del reconocimiento e indagación de este.

4. Con las trascendencias, que deben ser entendidas no solamente en una dimensión religiosa, sino también en dimensiones humanas históricas, lo cual nos permite relacionarnos con personajes trascendentales como los grandes artistas (Miguel Ángel, Leonardo Da Vinci, Juan Sebastián Bach, Miguel de Cervantes Saavedra y tantos otros que han trascendido su época y han dejado un legado que nos llega y continúa).

Esta vinculación la realiza el sujeto humano al interior de la cultura, razón por la cual vale detenernos un instante para saber cuál es la definición de cultura. Nos referimos aquí no a la cultura de la normativa jurídica colombiana (Ley 397 del 7 de agosto de 1997), sino a otra cultura cuyos elementos puedan ser más fácilmente distinguibles en la práctica, por lo cual tomaremos la de Declaración de Friburgo (Unesco y Organización Internacional de la Francofonía, 2007):

El término "cultura" abarca los valores, las creencias, las convicciones, los idiomas, los saberes y las artes, las tradiciones, instituciones y modos de vida por medio de los cuales una persona o un grupo expresa su humanidad y los significados que da a su existencia y a su desarrollo. (art. 2a)

En otras palabras, podríamos decir que la cultura es todo lo que el ser humano es capaz de producir como hijo de la sociedad que es. Por esta razón, interesa entender la cultura como aquello que tiene vinculación con las formas y los símbolos. Frente a esto, 
La cuestión de qué es la identificación debe aclararse a partir de las categorías que desde hace años promueve aquí ante ustedes, a saber, las de lo simbólico, lo imaginario y lo real (...).

Atengámonos a los primeros aspectos, los más evidentes, de la experiencia del duelo. El sujeto se abisma en el vértigo del dolor y se encuentra en cierta relación con el objeto desaparecido que de alguna manera nos es ilustrada por lo que ocurre en la escena del cementerio. Laertes se arroja a la tumba y, abraza al objeto cuya desaparición es causa de ese dolor. Es obvio que el objeto resulta entonces tener una existencia tanto más absoluta cuanto que ya no corresponde a nada que exista. (Lacan, 2014, p. 371)

\section{LA REPARACIÓN INTEGRAL}

Como hemos visto, la idea de reparación integral está fundamentada en el texto de la Convención americana de derechos humanos (Pacto de San José) (OEA, 1969) que, en su artículo 63.1, más allá de lo ya indicado, implica el otorgamiento de medidas tales como: a) la investigación de los hechos; b) la restitución de derechos, bienes y libertades; c) la rehabilitación física, psicológica o social; d) la satisfacción, mediante actos en beneficio de las víctimas; e) las garantías de no repetición de las violaciones; y f) la indemnización compensatoria por daño material e inmaterial (Calderón, 2013).

Cabe señalar que, en principio, dicha declaración solamente admitía como sujetos a los Estados, en tal sentido:

En el primer reglamento de la Corte IDH de julio de 1980, la Comisión interamericana era quien presentaba la demanda del caso ante la Corte Interamericana y representaba a las víctimas en todas las etapas, lo cual implicaba que en la audiencia pública la Comisión Interamericana de Derechos Humanos (en adelante "CIDH" o "Comisión Interamericana") en ocasiones acreditaba a las víctimas como asesores de la comisión para el caso. Con la reforma de 1996, se dio acceso a las víctimas a intervenir en la audiencia al exponer sus pretensiones en reparaciones, lo cual implicó escuchar las afectaciones específicas de las víctimas y sus necesidades para reestablecer su situación. Con la reforma reglamentaria de 2000, se incluyó la posibilidad de participar de modo autónomo e independiente en todas las etapas (excepciones preliminares, fondo y reparaciones, a través de su escrito de solicitudes, argumentos y pruebas (en adelante ESAP) y en las audiencias y en alegatos finales. Finalmente, con la reciente reforma de 2009, se modificó el papel de la Comisión Interamericana como garante del interés público interamericano y el inicio del proceso ante la Corte IDH con la remisión del informe de fondo. Las partes en litigio ante la Corte Interamericana son ahora los representantes junto con el Estado y con ello se pretende brindar mayor participación a las víctimas en el litigio internacional. (Calderón, 2013, p. 153)

Por lo anterior, la reparación del daño implica una obligación del Estado por su responsabilidad internacional y por ser un derecho fundamental de las víctimas.

Es significativo señalar que, para la Corte Interamericana de Derechos Humanos, el daño inmaterial sea el propio resultado de agresiones y vejámenes que las víctimas pueden haber sufrido por parte de los victimarios, en tanto que se puede experimentar un profundo sufrimiento de angustia, terror, impotencia e inseguridad. Este daño no requiere 
pruebas, cuestión que se amplía a su familia que también es objeto de tales sufrimientos $y$, por ende, tampoco requiere ser probado el daño inmaterial. Cabe añadir que el daño psicológico se configura por la alteración o modificación patológica del aparato psíquico como consecuencia de un trauma que desborda toda posibilidad de elaboración verbal o simbólica (Calderón, 2013).

En relación con esta definición del daño psicológico, si bien entendemos la concepción, nos parece muy radical por cuanto se debe entender que si la elaboración del trauma no se realiza de manera adecuada (como en los casos del estrés postraumático), no significa que no existan posibilidades de conseguir su reelaboración simbólica por medio de tratamientos especializados.

Así las cosas, la reparación integral comporta pues, al menos, tres aspectos principales: el reconocimiento de las vejaciones realizadas a las víctimas tanto directas como indirectas; la consideración que los daños generados tienen múltiples dimensiones que van desde el individuo afectado hasta el colectivo al cual se vincula $y$, por último, la integralidad de las medidas de reparación que buscan resarcir el daño y procurar una garantía de no repetición.

Dentro de las reparaciones en el sistema interamericano de protección de derechos humanos, afirma Rodríguez (1996) que la Corte Interamericana de Derechos Humanos, respecto del daño patrimonial, ha creado uniformidad en el modo de estimarlo. En cuanto al daño moral, ha existido unicidad sobre la justificación y la determinación de los beneficiarios, mas no respecto del cálculo del daño habida cuenta de las particularidades de cada asunto, pero indica que no deben seguirse los criterios civilistas usados en muchas legislaciones cuyo parámetro es una porción del daño patrimonial para calcular el moral por ser aje- no a la equidad, como quiera que los ingresos de las víctimas fluctuarían mucho dependiendo de una gran cantidad de variables. Respecto de otras medidas de satisfacción (teniendo en cuenta que este escrito fue producido antes de la última reforma del reglamento de la Corte Interamericana de Derechos Humanos), dice que se limitó a declarar que la sentencia condenatoria y la de reparaciones es ya una forma de indemnización.

Al decir de Theo Van Boven, relator especial de la ONU (como se cita en Rousset, 2011), la reparación integral puede presentarse como “1) la restitución; 2) la indemnización; 3) Proyecto de vida; 4) la satisfacción y las garantías de no-repetición" (p. 65).

En cuanto a las medidas de satisfacción que se enmarcan dentro del daño moral o inmaterial, podemos señalar que son respuestas a la idea de que el dolor y la aflicción surgen a propósito de las violaciones de derechos humanos sufridas por las víctimas, igualmente responden también a la obstaculización de valores altamente representativos para las víctimas y para sus condiciones de vida y son un equivalente a la violación de la integridad personal. En tal sentido, las medidas de satisfacción han de proveer a las víctimas de reparación en forma simbólica o representativa con impacto en la comunidad, el Estado y de manera pública (Rojas, 2010).

Por último, en cuanto a las garantías de no repetición, afirma Rojas (2010):

Las medidas de cesación y no repetición generan efectos sobre amplias situaciones de violaciones de derechos humanos. Por este motivo, se trata de garantías por excelencia, ya que tienen por finalidad corregir la falla que genera el ilícito a nivel interno. En su jurisprudencia constante, la Corte ha ordenado medidas que pueden clasificarse 
en tres renglones: acción y revisión legislativa, investigación y acción judicial, y acción ejecutiva. (p. 120).

Como se deja expuesto, la Corte Interamericana de Derechos Humanos ha venido generando procesos de ampliación del problema jurídico de la reparación y de las medidas de satisfacción y no repetición que la han ubicado en la vanguardia mundial frente a Europa y África por lo avanzado de sus mecanismos.

Lo que importa no es lo avanzado que se esté, sino que se logre involucrar no solamente una concepción de mundo y de vida mínimos en referencia con los derechos humanos, sino de reparar los daños que permitan a las comunidades y a los Estados cada día aumentar sus rasgos democráticos.

\section{LA REPARACIÓN COLECTIVA}

En Colombia, la Ley 975 (Congreso de Colombia, 2005) y la Ley 1448 (Congreso de la República de Colombia, 2011) son las normas que recogen los componentes de la reparación integral estructurados sobre la idea de "restitución", por la cual se entiende las acciones que conlleven a devolver a las víctimas a la situación inmediata anterior a las vejaciones sufridas, de "rehabilitación", que incluye atención médica y psicológica a las víctimas y familias en primer grado de consanguinidad, de "satisfacción" y "garantías de no repetición", que comprenden una multiplicidad de presupuestos como los de verificación de los hechos y la difusión pública de la verdad judicial, búsqueda de desaparecidos y fallecidos y sus identificaciones de manera que incluyan las tradiciones culturales para sus sepelios, decisiones judiciales que han de restablecer la dignidad de las víctimas, disculpas públicas por los hechos sucedidos, sanciones a los victima- rios y violadores de los derechos, prevenciones de nuevas violaciones a los derechos humanos $y$, finalmente, la formación en derechos humanos de los responsables de sus violaciones.

Ahora, cuando un colectivo ha sido víctima de alguno de los siguientes eventos: (a) menoscabo de derechos ocasionado por la violación de los derechos colectivos, (b) la violación sistemática de los derechos individuales de los miembros de los colectivos, o (c) el impacto colectivo de la violación de derechos individuales se entiende que es acreedor de una reparación colectiva.

En todo caso, la normativa de Colombia entiende que las medidas de reparación son tanto individuales como colectivas. Al hablar de las colectivas, el Decreto 4800 del 20 de diciembre de 2011 presenta cinco objetivos del Programa de Reparación Colectiva, a saber: 1) reconocimiento y dignificación de los sujetos colectivos victimizados, 2) reconstrucción del proyecto de vida colectivo y/o planes de vida y/o proyectos de etnodesarrollo, 3) recuperación psicosocial de las poblaciones y grupos afectados, 4) recuperación de la institucionalidad propia del Estado Social de Derecho, pluriétnico y multicultural, y 5) promoción de la reconciliación y la convivencia pacífica. Todo lo cual se estructura en tres componentes que agrupan lo siguiente: a) restablecimiento de las condiciones que permitan y potencien la existencia y el papel de comunidades, b) articulación de medidas materiales de reparación colectiva con otras medidas de la política pública y c) construcción de memoria histórica como aporte al derecho a la verdad del que son titulares los sujetos de reparación colectiva.

Así, la reparación colectiva se entiende como el conjunto de las acciones encaminadas a resarcir el daño colectivo ocasionado por la violación sistemática de los derechos humanos. Dentro de ella, se encuentran las medidas 
de reparación simbólica que "no pretenden reparar lo que se perdió, sino lo que representa aquello perdido, especialmente en la medida en que es imposible reparar algunos de los perjuicios sufridos por las víctimas" (Organización Internacional para las Migraciones, Misión en Colombia, 2012, p. 39).

La implementación de la reparación colectiva pasa por tres tipos de enfoques que deben integrarse para lograr una reparación integral, tal como afirma la Organización Internacional para las Migraciones, Misión en Colombia (2012). Así, se habla de un enfoque de impactos sociales y culturales que analiza los efectos ocasionados por las violaciones, un enfoque de derechos que mira los derechos afectados y los daños generados caso a caso, y el enfoque psicosocial, que se acerca a las afectaciones en salud mental y en recuperación del tejido social.

\section{LA REPARACIÓN CULTURAL}

El derecho ha venido señalando un camino vinculado con la reparación simbólica pues, a través de pequeños pasos, ha ampliado su significación simbólica y la ha deslizado hacia lo que hemos considerado en llamar "reparación cultural". Es así como la Corte Interamericana de Derechos Humanos ha generado una serie de medidas de satisfacción y garantías de no repetición, para lo cual ha propuesto ya más de treinta y seis medidas de referencias que han sido ordenadas por la Corte Interamericana de Derechos Humanos.

Estas medidas (que iniciaron con la mera lectura de sentencias, pasando por disculpas, monumentos, hospitales, escuelas, eventos reiterados, manifestaciones artísticas, entre otras) han puesto en escena un verdadero "deslizamiento" que da nacimiento a una reparación cultural. ¿Por qué? Porque, como vimos anteriormente, lo más característico del ser humano es su capacidad de simbolización y el uso de los lenguajes y, para estructurar un símbolo, solo es posible hacerlo entre las personas y al interior de una cultura.

Frente a las violaciones vividas en Colombia, se propone que tanto afectados como agresores comparten la misma visión del mundo. En nuestros tiempos, si algo define a la barbarie en la que estamos inmersos es justamente la acumulación del no saber qué hacer, por cuanto lo no sabido emerge como un significante característico de la época, mientras que todo lo sabido choca con una realidad que lo denuncia (cuando no ineficaz) reproductor de lo ya conocido por la siniestralidad de sus efectos. Así, nuestra propuesta es la instauración de lo no sabido como un significante capaz de lanzarnos a una pluridimensionalidad de soluciones.

Nos interesa resaltar que la idea de lo simbólico no es solamente como la entiende el derecho, frente a lo cual la psicología hace un importante aporte. Para entender la reparación cultural, es importante comprender que aquellos símbolos que son producidos por la comunidad pueden ser usados en diversas maneras, pero que, tratándose de justicia transicional, serían aquellas formas simbólicas producidas por la comunidad con el ánimo de morigerar el dolor de las víctimas, hablar elaboradamente (con cualquiera de los lenguajes hablados, escritos, pintados, musicalizados, danzados, actuados, etc.) de los sucesos acaecidos de violación de los derechos humanos y colectivos que sufrieron, aceptar en forma comunitaria tal verdad e incorporarla en su cultura, las que pueden facilitar el desarrollo de los duelos individuales y colectivos.

En vinculación con lo antes expuesto, la reparación cultural en el derecho no adquiere un verdadero sentido hasta que las acciones realizadas por parte del Estado sobre justicia y reparación surjan de las preguntas y el diálogo 
con la comunidad y, en particular, con las víctimas. Estas respuestas deben surgir de la cultura misma de la comunidad como producto del debate y la reflexión acerca del hecho. Entonces, se podrán proponer formas simbólicas enraizadas en esa cultura que habrán de colaborar en los procesos de duelos individuales y colectivos, verdad, aceptación de los hechos e incorporación de las víctimas y sus efectos a la cultura de la comunidad.

Para ello, resulta estratégica la forma de convocar, participar e involucrarse con la comunidad por parte de los agentes promotores de una reparación cultural, para lo cual constituye una experiencia interesante la relatada en el documento Del daño a la reparación colectiva: la experiencia de 7 casos emblemáticos (Organización Internacional para las Migraciones, Misión en Colombia, 2012).

Aquí, es importante entender que la cultura no es algo estático, sino dinámico y cambiante, pero que dadas las dinámicas que se propongan en el proceso de justicia transicional la comunidad puede reconocer ciertas limitaciones de su misma cultura y proponer su transformación, independientemente de que tales limitaciones sean fruto de violaciones de derechos humanos y colectivos. Ante esta perspectiva, la comunidad, los individuos e, incluso, el Estado deberán contribuir en la construcción de una cultura más estable, duradera y coherente con los derechos humanos como requerimientos mínimos para la dignidad y el desarrollo humano.

La reparación cultural de la que hablamos se construye desde abajo, centrada en las víctimas, sobre el légamo de la cultura y para la cultura democrática e incluyente: una simbolización culturalmente reparadora. Tal como señalábamos al inicio de este escrito, se trata de una propuesta estructurada para comunidades que poseen unos referentes identitarios muy fuertes, que han sufrido una violación sistemática de sus derechos humanos y/o derechos colectivos, con lo cual, estaríamos hablando de que las acciones para una reparación cultural deberán ser solicitadas a nombre de la comunidad.

Por último, aún no está lista la manera metodológica para acercarse a estas comunidades, pero podrán recogerse los señalamientos aquí bocetados, junto con las correspondientes autorizaciones de la comunidad, pues en la medida que la comunidad haga consciente en sus deliberaciones este proceso simbólico, es probable que pueda generar un proceso de reparación cultural que tenga soporte en varios aspectos de su cultura, como las ya realizadas por la Corte Interamericana de Derechos Humanos, numerosas y variadas (Bruno, 2013): publicación y difusión de la sentencia; realización de actos públicos de reconocimiento de responsabilidad; medidas educativas y de capacitación para víctimas; mecanismos de búsqueda de personas desaparecidas; búsqueda de los restos mortales de las víctimas; lugares adecuados para los restos mortales de las víctimas; reapertura de escuela y establecimiento de salud; suministro de bienes y servicios básicos; designación de días dedicados a la memoria de las víctimas; creación de monumentos, bustos y placas; denominación de calles, plazas y escuelas; realización y difusión de audiovisuales documentales; establecimiento de cátedras, cursos o becas con el nombre de las víctimas; mantenimiento y mejora de capiIla; capacitación de agentes estatales; reforma y adecuación de normas; reforma constitucional por permitir censura previa; tipificación de delitos; derecho al recurso contra la sentencia condenatoria ante un tribunal superior; procedimiento en casos de pena de muerte; mecanismos para reclamar tierras ancestrales; regulación de la consulta previa a comunidades

Omnia. Derecho y sociedad, núm. 3, 2020: 37-54 
indígenas; acceso a técnicas de reproducción asistida; legislación electoral; legislación sobre el reclutamiento de menores de edad para el servicio militar; normas relacionadas con la independencia judicial,; reformas legislativas y otras medidas para garantizar la investigación efectiva de desapariciones forzadas; garantías en procedimientos administrativos y contenciosos administrativos; modificación y erradicación de prácticas violatorias de derechos humanos; actuación de las fuerzas armadas y de seguridad; personas privadas de libertad: condiciones de detención y trato respetuoso de sus derechos; consulta previa a la realización de actividades en territorios de pueblos indígenas; acceso público a información y archivos estatales; acceso a información sobre prestaciones de salud y seguridad social para personas con discapacidad; interpretaciones judiciales respecto de la relación entre jueces provisorios y la garantía de independencia judicial; modificación de prácticas y desarticulación de estereotipos discriminatorios; medidas de afirmación positiva respecto de personas en situación de vulnerabilidad y, por último, investigación de los hechos, acciones que se han realizado por la Corte Interamericana de Derechos Humanos y cuyos sentencias base pueden leerse en el pie de página².

${ }^{2}$ Corte IDH. Caso de las Hermanas Serrano Cruz Vs. El Salvador; Caso 19 Comerciantes Vs. Colombia. Fondo, Reparaciones y Costas; Corte IDH. Caso de la Comunidad Moiwana Vs. Suriname. Excepciones Preliminares, Fondo, Reparaciones y Costas. Sentencia 15 de junio de 2005; Corte IDH. Caso Juan Humberto Sánchez Vs. Honduras. Excepción Preliminar, Fondo, Reparaciones y Costas. Sentencia de 7 de junio de 2003; Corte IDH. Caso Aloeboetoe y otros Vs. Surinam. Reparaciones y Costas. Sentencia de 10 de septiembre de 1993; Corte IDH. Caso Comunidad Indígena Yakye Axa Vs. Paraguay. Fondo Reparaciones y Costas. Sentencia 17 de junio de 2005; Corte IDH Caso Myrna Mack Chang Vs. Guatemala. Fondo, Reparaciones y Costas. Sentencia de 25 de noviembre de 2003; Corte IDH Caso Myrna Mack Chang Vs. Guatemala. Fondo, Reparaciones y Costas. Sentencia de 25 de noviembre de 2003; Corte IDH Caso de los hermanos Gómez Paquiyauri vs. Perú. Fondo, Reparaciones y Costas. Sentencia de 8 de julio de 2004; Corte IDH Caso Gudiel Álvarez y otros ("Diario Militar") Vs. Guatemala. Fondo, Reparaciones y Costas. Sentencia de 20 de noviembre de 2012; Corte IDH. Caso Contreras y otros Vs. El Salvador. Fondo, Reparaciones y Costas. Sentencia de 31 de agosto de 2011; Corte IDH. Caso González Medina y familiares Vs. República Dominicana. Excepciones Preliminares, Fondo, Reparaciones y Costas. Sentencia de 27 de febrero de 2012; Corte IDH. Caso Masacres de El Mozote y lugares aledaños Vs. El Salvador. Fondo, Reparaciones y Costas. Sentencia de 25 de octubre de 2012; Corte IDH. Caso Huilca Tecse Vs. Perú. Fondo, Reparaciones y Costas. Sentencia de 3 de marzo de 2005; Corte IDH. Caso Masacre Plan de Sánchez Vs. Guatemala. Reparaciones. Sentencia de 19 de noviembre 2004; Corte IDH Caso Myrna Mack Chang Vs. Guatemala. Fondo, Reparaciones y Costas. Sentencia de 25 de noviembre de 2003; Corte IDH Caso Fleury y otros Vs. Haití. Fondo y Reparaciones. Sentencia de 23 de noviembre de 2011; Corte IDH. Caso Torres Millacura y otros Vs. Argentina. Fondo, Reparaciones y Costas. Sentencia de 26 de agosto de 2011; Corte IDH. Caso Bulacio Vs. Argentina. Fondo, Reparaciones y Costas. Sentencia de 18 de septiembre de 2003; Corte IDH Caso Almonacid Arellano y otros Vs. Chile. Excepciones Preliminares, Fondo, Reparaciones y Costas. Sentencia de 26 de septiembre de 2006; Caso Cabrera García y Montiel Flores Vs. México. Excepción Preliminar, Fondo, Reparaciones y Costas. Sentencia de 26 de noviembre de 2010; Corte IDH Caso "La Última Tentación de Cristo" (Olmedo Bustos y otros) Vs. Chile. Fondo, Reparaciones y Costas. Sentencia de 5 de febrero de 2001; Corte IDH. Caso Loayza Tamayo Vs. Perú. Reparaciones y Costas. Sentencia de 27 de noviembre de 1998; Corte IDH. Caso Herrera Ulloa Vs. Costa Rica. Excepciones Preliminares, Fondo, Reparaciones y Costas. Sentencia de 2 de julio de 2004; Corte IDH. Caso Mohamed Vs. Argentina. Excepción Preliminar, Fondo, Reparaciones y Costas. Sentencia de 23 noviembre de 2012; Corte IDH. Caso Fermín Ramírez Vs. Guatemala. Fondo, Reparaciones y Costas. Sentencia de 20 de junio de 2005; Corte IDH. Caso Comunidad Indígena Yakye Axa Vs. Paraguay. Fondo, Reparaciones y Costas. Sentencia 17 de junio de 2005; Corte IDH. Caso Pueblo Indígena Kichwa de Sarayaku Vs. Ecuador. Fondo y Reparaciones. Sentencia de 27 de junio de 2012; Corte IDH. Caso Artavia Murillo y otros (Fertilización in vitro) Vs. Costa Rica. Excepciones Preliminares, Fondo, Reparaciones y Costas Sentencia de 28 noviembre de 2012; Corte IDH. Caso López Mendoza Vs. Venezuela. Fondo Reparaciones y 


\section{REFERENCIAS BIBLIOGRÁFICAS}

Botero, E., Solis, R., López, M. y Velásquez, E. (2000). Duelo, acontecimiento y vida. Consideraciones sobre la atención psicosocial: caso Trujillo, Valle. Bogotá: Escuela Superior de Administración Pública e Instituto de Derechos Humanos "Guillermo Cano".

Bruno, R. (2013). Las medidas de reparación en la jurisprudencia de la Corte Interamericana de Derechos Humanos: alcances y criterios para su determinación. [Tesis de maestría]. La Plata: Facultad de Ciencias Jurídicas y Sociales, Universidad Nacional de La Plata.

Calderón, J. (2013). La reparación integral en la jurisprudencia de la Corte Interamericana de Derechos Humanos: estándares aplicables al nuevo paradigma mexicano. En Mac-Gregor Poisot, Caballero Ochoa y Steiner (Coord.). Derechos Humanos en la Constitución: Comentarios de Jurisprudencia Constitucional e Interamericana. México: Instituto de investigaciones jurídicas, Suprema Corte de Justicia de la Nación y Fundación Konrad Adenauer.

Castoriadis, C. (1993). La institución imaginaria de la sociedad. Buenos Aires: Tusquets editores. Decreto 4800. Por el cual se reglamenta la Ley 1448 de 2011 y se dictan otras disposiciones. (20 de diciembre de 2011). Diario Oficial de Colombia N 48.280. Bogotá D. C., Colombia.

Escudero, R. (2017). Debatiendo sobre la Justicia transicional: memoria, perdón y castigo. En Larrañaga, P., Cerdio, J. y Salazar, P. Entre la libertad y la igualdad ensayos críticos sobre la obra de Rodolfo Vásquez, tomo 1, pp. 99-115. México: Universidad Nacional Autónoma de México, Instituto de Investigaciones Jurídicas, Instituto de Estudios Constitucionales del Estado de Querétaro, Instituto Tecnológico Autónomo de México.

Guilis, G. y Equipo de Salud Mental del CELS. (s.f.). El concepto de reparación simbólica. [Mimeo].

Hinestrosa, F. (s.f.). Derecho Civil. Obligaciones. Colombia: Universidad Externado de Colombia.

Lacan, J. (1953). Lo simbólico, lo imaginario y lo real. [Conferencia]. Recuperado de https:// lecturalacaniana.com.ar/lo-simbolico-loimaginario-y-lo-real/

Costas. Sentencia de 1 de septiembre de 2011; Corte IDH. Caso Vargas Areco Vs. Paraguay. Sentencia de 26 de septiembre de 2006; Corte IDH. Caso Chocrón Chocrón Vs. Venezuela. Excepción Preliminar, Fondo, Reparaciones y Costas. Sentencia de 1 de julio de 2011; Corte IDH. Caso González Medina y familiares Vs. República Dominicana. Excepciones Preliminares, Fondo, Reparaciones y Costas. Sentencia de 27 de febrero de 2012; Corte IDN Caso Barbani Duarte y Otros Vs. Uruguay. Fondo, Reparaciones y Costas. Sentencia de 13 de octubre de 2011; Corte IDH Caso Myrna Mack Chang Vs. Guatemala. Fondo, Reparaciones y Costas. Sentencia de 25 de noviembre de 2003; Corte IDH. Caso Fermín Ramírez Vs. Guatemala. Fondo, Reparaciones y Costas. Sentencia de 20 de junio de 2005; Corte IDH. Caso Díaz Peña Vs. Venezuela. Excepción Preliminar, Fondo, Reparaciones y Costas. Sentencia de 26 de junio de 2012; Corte IDH. Caso Juan Humberto Sánchez Vs. Honduras. Excepción Preliminar, Fondo, Reparaciones y Costas. Sentencia de 7 de junio de $2003 ; \mathrm{Corte}$ IDH. Caso Pueblo Indígena Kichwa de Sarayaku Vs. Ecuador. Fondo y Reparaciones. Sentencia de 27 de junio de $2012 ;$ Corte IDH. Caso Contreras y otros Vs. El Salvador. Fondo, Reparaciones y Costas. Sentencia de 31 de agosto de 2011 ; Corte IDH. Caso Furlan y Familiares Vs. Argentina. Excepciones Preliminares, Fondo, Reparaciones y Costas. Sentencia de 31 de agosto de 2012; Corte IDH. Caso Chocrón Chocrón Vs. Venezuela. Excepción Preliminar, Fondo, Reparaciones y Costas. Sentencia de 1 de julio de 2011; Corte IDH. Caso Atala Riffo y Niñas Vs. Chile. Fondo, Reparaciones y Costas. Sentencia del 24 de febrero de 2012; Corte IDH. Caso Furlan y Familiares Vs. Argentina. Excepciones Preliminares, Fondo, Reparaciones y Costas. Sentencia de 31 de agosto de 2012; Corte IDH. Caso García y Familiares Vs. Guatemala. Fondo, Reparaciones y Costas. Sentencia de 29 noviembre de 2012; Corte IDH Caso Forneron e hija Vs. Argentina. Fondo, Reparaciones y Costas. Sentencia de 27 de abril de 2012. 
Lacan, J. (1971). El estadio del espejo como conformador del yo tal como se revela en la experiencia psicoanalítica. En Los escritos de Jaques Lacan. España: Siglo XXI Editores.

Lacan, J. (1987). Seminario 11. Los cuatro conceptos fundamentales del psicoanálisis. Buenos Aires: Paidós.

Lacan, J. (2014). Seminario 6. El deseo y su interpretación, 1958-1959. Buenos Aires: Paidós.

Ley 957. Por la cual se dictan disposiciones para la reincorporación de miembros de grupos armados organizados al margen de la ley, que contribuyan de manera efectiva a la consecución de la paz nacional y se dictan otras disposiciones para acuerdos humanitarios. (25 de julio de 2005). Congreso de Colombia. Diario Oficial de Colombia $N^{\circ}$ 45.980. Recuperado de https://www. fiscalia.gov.co/colombia/wp-content/ uploads/2013/04/Ley-975-del-25-de-julio-de-2005-concordada-con-decretos-ysentencias-de-constitucionalidad.pdf

Ley 1448. Por la cual se dictan medidas de atención, asistencia y reparación integral a las víctimas del conflicto armado interno y se dictan otras disposiciones. (10 de junio de 2011). Congreso de la República de Colombia. Diario Oficial de Colombia $\mathrm{N}^{\circ}$ 48096. Recuperado de https://www.unidadvictimas.gov.co/sites/default/files/documentosbiblioteca/ley-1448-de-2011.pdf

Mancipe González, A. (2005). Los perjuicios inmateriales en la responsabilidad extracontractual del Estado en Colombia. [Trabajo de grado]. Colombia: Universidad Externado de Colombia. Recuperado de https://www. javeriana.edu.co/biblos/tesis/derecho/ dere7/DEFINITIVA/TESIS\%2020.pdf [15 de agosto de 2019].

Nanclares, J. y Gómez, A. (2017). La reparación: una aproximación a su historia, presente y prospectiva. Civilizar Ciencias Sociales y Hu- manas, 17(33), pp. 59-80. Recuperado de https://revistas.usergioarboleda.edu.co/ index.php/ccsh/article/view/899

O'Donell, G. (1994). Delegative Democracy. Journal of Democracy, 5(1), pp. 55-69. Estados Unidos: National Endowment for Democracy and The Johns Hopkins University Press.

Organización de los Estados Americanos. (22 de noviembre de 1969). Convención americana sobre derechos humanos (Pacto de San José). San José, Costa Rica.

Organización Internacional para las Migraciones, Misión en Colombia. (2012). Del daño a la reparación colectiva: la experiencia de 7 casos emblemáticos. Recuperado de https:/publications.iom.int/system/files/ pdf/del_dano.pdf

Oxfam International. (2018). Premiar el trabajo, no la riqueza. Recuperado de https:// oxfam.app.box.com/s/eosi27xj7nxuyywysr06d734ct1xyuev/file/267209868165

Patiño, A. (2010). Las reparaciones simbólicas en escenarios de justicia transicional. Revista Latinoamericana de derechos Humanos, 21(2), pp. 51-61. Recuperado de http:// www.corteidh.or.cr/tablas/r27292.pdf

Puccetti, G. (2017). La reparación simbólica como paradigma de respuesta ante violaciones a derechos fundamentales. [Tesis de maestría]. Madrid: Instituto Universitario en Estudios Avanzados "Bartolomé de las Casas", Universidad Carlos 3 de Madrid.

Rodríguez, V. (1996). Las reparaciones en el sistema interamericano de protección de Derechos Humanos. Revista Internacional de Derechos Humanos, 23, pp. 130-150. Recuperado de https://www.iidh.ed.cr/IIDH/ media/1620/revista-iidh23.pdf

Rojas, J. J. (2010).

Rousset, A. J. (2011). El concepto de reparación integral en la jurisprudencia de la Corte Interamericana de Derechos Humanos. Re- 
vista Internacional de Derechos Humanos, 1, pp. 59-79. Recuperado de http://www. cladh.org/wp-content/uploads/2012/07/ a1-n1-2011-art03.pdf

Saussure, F. (1993). Curso de lingüística general. Madrid: Alianza Editorial.
Unesco y Organización Internacional de la Francofonía. (7 de mayo de 2007). Declaración de Friburgo. Recuperado de https:// culturalrights.net/descargas/drets_culturals239.pdf 
